\title{
REFLEXÕES SOBRE A PECUÁRIA LEITEIRA NO OESTE CATARINENSE: IMPACTOS COOPERATIVISTAS PARA O DESENVOLVIMENTO REGIONAL
}

\author{
REFLECTIONS ON DAIRY PRODUCTION IN THE WESTERN \\ REGIONOFSANTA CATARINA: COOPERATIVE IMPACTS \\ FOR REGIONAL DEVELOPMENT
}

\author{
Natália Carrão Winckler \\ Instituto Federal Sul-Rio-Grandense - RS - Brasil
}

Gisele Trindade Molinari

\begin{abstract}
Resumo
Este artigo faz uma reflexão sobre a evolução histórica da produção do leite no Oeste Catarinense nas últimas décadas. O foco do trabalho recai sobre diferentes influências na configuração desse setor produtivo, entre elas o cooperativismo e suas nuances. Para embasar a discussão, realizou-se entrevistas com sete especialistas, investigando como ocorreu a inserção e as mudanças na pecuária leiteira ao longo dos anos e sua colaboração para o desenvolvimento regional. As análises demonstram que, diante da demanda por especialização e altos investimentos em novas tecnologias de produção em avicultura e suinocultura, os quais seriam potenciais fatores de exclusão dos produtores rurais menos capitalizados, a pecuária leiteira possibilitou a muitos destes permanecerem no meio rural. De um lado, fatores institucionais, legais e mercadológicos vêm pressionando os produtores de suínos e aves e, paralelamente, os produtores de leite na realização de mudanças de tecnologia de produção. Por outro lado, isso também influencia sobre as estratégias desenvolvidas pelos produtores de leite para a manutenção de suas atividades, com o suporte de associações e cooperativas voltadas para o desenvolvimento da região.
\end{abstract}

Palavras-chave: Cooperação. Cadeia Produtiva do Leite. Agricultura familiar.

\section{Abstract}

This article reflects on the historical evolution of dairy production in Western of Santa Catarina in recent decades. The focus of this work lies on different influences over the configuration of this productive sector, including cooperativism and its nuances. To support the discussion, we interviewed seven experts and investigated how occurred insertion and changes in dairy farming over the years and how it has contributed to regional development. The analysis shows that, given the demand for expertise and high investment in new production technologies in poultry and swine production, which would be potential exclusion criteria for less capitalized farmers, the dairy farming has enabled many of these to remain in the countryside. On the one hand, institutional, legal and market factors have been pushing on poultry and swineproducers and dairy farmers for production technology changes. On the other hand, this also influences on the strategies of dairy farmers for maintaining their activities, counting with the support of associations and cooperatives oriented to the development of the region..

Key-words: Cooperation. Dairy chain. Family agriculture. 


\section{INTRODUÇÃO}

Este trabalho faz uma reflexão sobre a evolução histórica da produção de leite no Oeste Catarinense. O desenvolvimento regional foi retomado e impulsionado pela produção leiteira nos últimos 30 anos, contrapondo-se a um cenário de êxodo rural e descapitalização do homem do campo, tendo como atores algumas ações e organizações cooperativistas criadas pelos produtores rurais, especificamente pelos agricultores familiares.

É de conhecimento geral que a industrialização característica do século XX chegou também ao meio rural. Em meados das décadas de 1960 e 1970, o fenômeno da Revolução Verde levou maior produtividade ao campo com o uso de máquinas agrícolas e tecnologias diferenciadas, que exigiam menos força de trabalho e maior capital dos produtores rurais. Contudo, esse fenômeno se fez presente, inclusive, na região do Oeste Catarinense, e não resultou somente em maior produtividade; houve, também, a exclusão de muitos produtores rurais com menor capacidade de investimento para atender às demandas da indústria.

Tradicionalmente, o Oeste de Santa Catarina tem como base econômica a produção agropecuária. Há menos de um século, essa região foi colonizada por descendentes de alemães e italianos que, inicialmente, extraíam madeira e depois passaram a produzir suínos e aves. Com o desenvolvimento tecnológico chegando ao campo e a pressão do mercado e das agroindústrias instaladas na região, já em meados dos anos 1980, os produtores rurais despertaram para um novo panorama: ou investiam na produção para que se mantivessem fornecedores das agroindústrias, ou teriam que buscar outras fontes de renda (geralmente, no meio urbano).

Nessa época, a produção de leite, que era uma atividade de subsistência, passou a ser vista como uma alternativa viável economicamente, pois exigia baixo custo de implantação e possibilitaria o ganho de renda mensal. Dessa forma, muitas famílias desistiram de abandonar o meio rural e investiram nessa produção. Além disso, fatores culturais dos produtores rurais, como o hábito de trabalhar de forma coletiva, podem ter permitido um fortalecimento das suas atividades.

A partir desse contexto, este trabalho faz uma reflexão sobre a evolução desse processo histórico de fortalecimento da produção leiteira no Oeste Catarinense e sua expressividade sobre o desenvolvimento regional. O artigo está estruturado em introdução, revisão de literatura, metodologia, discussão e considerações finais.

\section{REVISÃO DE LITERATURA}

O desenvolvimento regional está envolto em discussões que envolvem desde aspectos econômicos, como o Produto Interno Bruto - PIB, às relações interpessoais e culturais. No caso do Brasil, em que as regiões possuem características produtivas muito distintas, é possível perceber fortes diferenças quanto ao desenvolvimento regional, os atores envolvidos e as estratégias utilizadas.

Uma das regiões brasileiras que contou com expressivo desenvolvimento 
nas últimas décadas foi a região Oeste de Santa Catarina. Sua matriz produtiva se alterou nos últimos anos, chegando a destacar-se como um dos maiores e melhores produtores de leite do país, o que provocou um grande impacto no desenvolvimento regional, especialmente a partir de estratégias cooperativas utilizadas pelos diferentes agentes daquele território. Essa evolução será apresentada a seguir.

\subsection{Breve histórico da produção de leite no Oeste Catarinense}

O Oeste de Santa Catarina teve sua evolução pautada sobre diferentes matrizes produtivas ao longo dos últimos 90 anos. Após a chegada dos colonizadores alemães e italianos, das "Colônias Velhas" do Rio Grande do Sul nos anos 1920 (ALVES; MATTEI, 2006), houve a exploração de madeira, fumo (até 1950), suínos e aves. De acordo com Paim (2006), a partir de 1950, inúmeras indústrias e frigoríficos de suínos e aves receberam incentivos governamentais para se instalarem na região.

$\mathrm{Na}$ década de 1970, as agroindústrias adotaram um sistema produtivo chamado de integração, baseado em uma parceria entre produtor e indústria, a qual controla todo o sistema de produção (ração animal, quantidade de produção e de abate, assistência técnica e propostas de melhorias ao processo produtivo). Porém, esse novo sistema era bastante diferente do tradicional, já utilizado pelos produtores. Essa mudança gerou resistência entre os produtores, conforme afirma Paim (2006, p.11) e uma resposta das indústrias.

Para enquadrar todos os produtores dentro dos padrões estabelecidos, foi inventada uma doença chamada peste suína africana. Assim criou-se o pretexto para matar todos os porcos da raça comum e impor a nova raça. Os novos porcos precisaram ser produzidos dentro de determinados padrões de higiene e alimentação. Quem não procedeu como a agroindústria determinou foi sendo eliminado, seus animais não foram mais aceitos.

Essa integração entre produtores e indústria gerou uma verticalização da produção que, de acordo com Rover e Lanzarin (2008), demandou a adaptação de instalações e tecnologias de produção, levando os produtores a descapitalizar-se e diminuir a renda familiar. Alves e Mattei (2006) também apontam que as indústrias priorizavam produtores de maiores escalas produtivas e localizados mais próximos de suas plantas industriais.

Diante desse cenário, alguns produtores buscaram nas cidades melhores condições de vida, enquanto outros buscavam na diversificação de atividades outras fontes de renda. A produção de leite, que até então era de subsistência, passou a ter maior representatividade na formação da renda das famílias daquela região. Diferentemente da suinocultura e da avicultura, que eram atividades de produção importantes na economia regional, o leite tinha benefícios como menor barreira de entrada no mercado, possibilidade de ampliar a escala produtiva gradualmente, além das inúmeras formas de agregação de valor ao produto na propriedade rural, como a confecção de queijos, doces, entre outros produtos e subprodutos. Entre os benefícios socioculturais e ambientais, a produção de leite 
absorvia a mão de obraociosa e mantinha tradições histórico-culturais, o uso econômico e a conservação dos recursos naturais, utilizando áreas de terra que não eram aptas para a lavoura (DORIGON, 2008).

Apesar de todos os benefícios, o leite sofria com o tabelamento de preços e a baixa regulamentação da atividade, com cadeia de produção curta e comércio local. Assim, o produto tinha qualidade e produtividade baixas. Com a abertura econômica brasileira na década de 1990, o leite brasileiro se viu ainda mais ameaçado pelos produtos importados. Em menos de 10 anos, o setor passou por uma grande transformação, com o fim do tabelamento e diversas empresas que adotaram estratégias de fusão e aquisição (a Parmalat, por exemplo, adquiriu 22 plantas industriais entre 1989 e 1999), provocando o aumento da concorrência entre produtores rurais, que buscavam, então, fornecer a matéria-prima para as indústrias de laticínios (MAGALHÃES, 2006).

Desafios começaram a surgir para os produtores rurais que negociavam com os laticínios, entre eles a demanda por melhor qualidade e quantidade de leite. Muitos pequenos produtores, com frequência os associados às cooperativas, foram incapazes de realizar investimentos exigidos pelos laticínios. Conforme afirmam Rover e Lanzarin (2008, p.3):

\footnotetext{
este setor que representou a principal alternativa econômica dos últimos anos aos pequenos agricultores da região, tem revelado crescente seletividade, face aos custos de investimento e escala de produção que começa a exigir. Isto poderá ocasionar alguns limites para o desenvolvimento da atividade, promovendo uma nova fase de exclusão socioeconômica dos agricultores.
}

Adicionalmente, regulamentações federais por intermédio do Ministério da Agricultura, Pecuária e Abastecimento - MAPA vêm assombrando os produtores de leite mais tradicionais, como é o caso da Instrução Normativa 51 (IN51), lançada em 2002, mas ainda em fase de implantação. O objetivo é melhorar a qualidade do leite cru por meio da regulamentação e da fiscalização, tornando este produto competitivo no mercado interno e internacional (WINCK, 2007). Mais recentemente, a IN51 passou por um processo de modernização a fim de acompanhar as tendências mundiais do setor, conforme Winck (2012), com a publicação da Instrução Normativa 62 (IN62) em dezembro de 2011. A IN62 compõe-se de aspectos a serem cumpridos por todos os atores envolvidos na produção de leite, incluindo novos regulamentos técnicos para produção, identidade e qualidade do leite, além de condições para a refrigeração na propriedade rural e o transporte do produto até a indústria (WINCK, 2012).

Assim, ao longo dos anos, da mesma forma que ocorreu com a suinocultura e a avicultura, a pecuária leiteira passou a ser alvo de diferentes pressões institucionais legais que exigem especialização e investimentos em tecnologia de produção. Para Medeiros e Valencio (2008, p. 9), "a pecuária bovina de leite de base familiar revela-se como um modo de vida tradicional em flagrante processo de transição devido a ter-se tornado um dos focos das instituições modernizadoras do meio rural". Aqueles produtores que se mantêm no modo tradicional de produção estão buscando se adaptar ao novo cenário competitivo por meio de novos formatos organizacionais ou agregação de valor ao produto. De acordo com Mior (2008), alguns produtores destinam a produção para a indústria e outros 
realizam atividades ligadas a redes de pequenas agroindústrias, produção artesanal, orgânica, ecológica ou colonial. Conforme Tesche (2007), as redes permitem o acesso a novas tecnologias e a reunião de forças para enfrentar o oligopsônio da cadeia produtiva do leite.

O alto custo de captação de leite pelas indústrias faz da estrutura produtiva e da localização das propriedades fatores estratégicos importantes (SCHUBERT; NIEDERLE, 2009). A lógica de modernização envolvida nesse cenário provoca perdas de características da produção interiorizadas pelos produtores há gerações, que vão desde o empirismo da ordenha manual da vaca até técnicas corporais (MEDEIROS; VALENCIO, 2008). Há, portanto, diferenças entre as formas de organização das propriedades, além da comercialização que podem ser feita em grupos.

Os grupos de produtores resultaram em diversos organismos como associações, conselhos e sindicatos representativos dos pequenos agricultores, os quais Badalotti (2003) define como uma composição social de agentes, uma Rede de Viabilização da Agricultura Familiar. Para a autora, os princípios envolvidos nas ações desses grupos são cooperação agrícola, agroecologia, solidariedade entre grupos de agricultores e autogestão, entre outras características que valorizam a cultura local.

Nas últimas décadas, o Oeste Catarinense contou com organizações como a Associação dos Pequenos Produtores do Oeste Catarinense - APACO e a Associação das Cooperativas e Associações de Produtores Rurais do Oeste de Santa Catarina - Ascooper, que atuam fortemente sobre a cadeia produtiva do leite para viabilizar a agricultura familiar na região. A APACO foi criada em 1989 e deu origem à Ascooper, criada em 2002 e mais focada na produção de leite. A função dessas organizações é a de apoiar o produtor na comercialização de produtos, compra de insumos, criar parcerias com órgãos públicos, capacitar os produtores, facilitando a sua inserção nos mercados competitivos, além de realizar projetos que contribuem para o desenvolvimento regional (ANDION, 2007).

A APACO, conforme demonstra estudo realizado por Andion (2007), desenvolveu relações com agentes diversos, em escala internacional, nacional, estadual, regional e local. Por exemplo: Fairtrade Labelling Organization - FLO, Ministério do Meio Ambiente - MMA, Ministério do Desenvolvimento Agrário MDA, Agência de Desenvolvimento da Igreja Católica da Alemanha - Misereor, Central Única de Trabalhadores - CUT, Unidade Central das Agroindústrias Familiares do Oeste Catarinense - UCAF, Empresa de Pesquisa Agropecuária e Extensão Rural de Santa Catarina - Epagri, sistemas de crédito, universidades, cooperativas, certificadoras de orgânicos, organizações de movimentos sociais, entre outros.

A Ascooper é formada por inúmeras cooperativas e mantida por contribuições mensais feitas pelos produtores associados. Ela atua na articulação do comércio, assistência e acompanhamento aos produtores da região e cada cooperativa atua sob a lógica da autogestão, o que se reflete na forma e nos preços de negociação do leite com os associados (SCHUBERT; NIEDERLE, 2009).

O leite tem se mostrado uma das principais fontes de renda da região. Dados do Instituto Brasileiro de Geografia e Estatística - IBGE, (2006) apontam que, em 1990, havia em torno de 25 mil propriedades familiares produtoras de 
leite no Oeste Catarinense. Já no último censo agropecuário do IBGE, de 2006, há registro de 51.614 estabelecimentos agropecuários produtores de leite de vaca, sendo 92,43\% pertencentes à agricultura familiar, distribuídos nos 118 municípios do Oeste Catarinense. Em outras palavras, a produção de leite em Santa Catarina cresceu mais de $340 \%$ em 30 anos $^{1}$.

Diante desse contexto é que se desenvolvem as reflexões sobre os impactos que a produção de leite teve no desenvolvimento da região. O tópico a seguir tratará das formas associativas em atividades do meio rural, que são alguns dos aspectos relevantes para o desenvolvimento regional.

\subsection{Organizações associativas em atividades do meio rural}

Organizações do tipo associativas costumam pressupor um paradoxo, no caso, entre competição e cooperação. Embora haja formatos diferenciados, 0 embasamento situa-se em superar a competição através da cooperação, mostrando-se como alternativa significante para contornar problemas econômicos e sociais principalmente. Assim, o associativismo e o cooperativismo são duas formas relevantes de participação social.

O associativismo é motivado pela representação e defesa de interesses de uma união de pessoas, as quais buscam alcançar objetivos comuns, seja uma melhoria técnica, profissional, econômica, cultural ou social. O cooperativismo propõe um modelo de associação com as características de propriedade, gestão e participação cooperativas (RIOS, 2007).

As primeiras propostas, com ideias de ajuda mútua, igualdade, associativismo e autogestão, foram representadas por socialistas utópicos como Robert Owen, Louis Blanc, Charles Fourier, entre outros. O cooperativismo surge na Europa do século XVIII, como expressão de um movimento operário contrário à exploração, em meio ao contexto do desenvolvimento capitalista industrial na época. A criação da Sociedade dos Probos Pioneiros de Rochdale, em 1844, na Inglaterra, é apontada como marco histórico. Era uma cooperativa de consumo, organizada por operários que visavam à melhoria de sua situação econômica e bem-estar comum. Com ela nascem os princípios do cooperativismo; embora, anos mais tarde, tenha se afastado de seus ideais originais ${ }^{2}$.

No Brasil, o surgimento do cooperativismo, por volta do século XIX, relaciona-se às elites econômicas e políticas em uma economia predominantemente agroexportadora, segundo Rios (2007). A maior parte dos pesquisadores destaca, como primeira experiência, uma cooperativa de consumo fundada por funcionários em Ouro Preto (MG), em 1889. Também é relevante o

\footnotetext{
1 A produção de leite anual do Estado teve registros superiores a 409,8 milhões de litros em 1975, a 603,7 milhões de litros em 1985, a 869,4 milhões de litros em 1995 e a 1,3 bilhões de litros em 2006 (IBGE, 2006).

2 Os atuais princípios do cooperativismo são: 1) adesão voluntária e livre; 2) gestão democrática; 3) participação econômica dos membros; 4) autonomia e independência; 5) educação, formação e informação; 6) intercooperação; e 7) interesse pela comunidade.
} 
registro de uma cooperativa de crédito, que remonta ao ano de 1902, em Nova Petrópolis (RS), já que passou a auxiliar econômica e socialmente os imigrantes que chegavam ao Rio Grande do Sul.

Enfim, cooperativas e associações foram sendo constituídas por motivação da sociedade civil, da classe produtiva ou do poder público. Para Silva e Lago (2010), é desafio constante para o cooperativismo cumprir seu duplo propósito enquanto empresa econômica e sociedade de pessoas doutrinamente regida por princípios. As cooperativas possuem uma arquitetura organizacional diferente, destaca Bialoskorski Neto (2000), pois, no que tange à distribuição de direitos de propriedade, por exemplo, apesar de adotarem as mesmas estratégias de negócios em geral, elas são estruturas intermediárias e espontâneas, situadas entre as economias particulares dos cooperados e o mercado.

Segundo o Relatório de Atividades da Organização das Cooperativas Brasileiras - OCB, existem 6.603 cooperativas, distribuídas em 13 ramos diferentes, em todo Brasil. Dessas, o setor agropecuário conta com 1.561 unidades (OCB, 2014). No ramo agropecuário, estão as cooperativas de produtores rurais, focadas na produção em comum e/ou nos serviços de recebimento, de comercialização da produção conjunta, de armazenamento, de industrialização, de assistência técnica, educacional e social, prestados aos seus associados (RIOS, 2007).

A atuação de cooperativas e de associações contribui para o desenvolvimento de regiões rurais, visto que apoiam e viabilizam produtores rurais e atividades desenvolvidas no campo, além do seu envolvimento com a sociedade. $O$ associativismo mostra-se fundamental para o debate e a defesa de demandas dos produtores.

Assim como, para Ilha (2008, p. 28) "uma cooperativa, que se estabelece como instrumento de desenvolvimento econômico e social, faz dessa organização algo significativamente diferente das demais empresas, contribuindo para o incremento do capital social".

O Oeste Catarinense conta, como mencionado, com cooperativas e associações de produtores que tem viabilizado a produção leiteira e a permanência dos produtores no meio rural. A existência das associações, mobilizando a organização, orientando os produtores e promovendo ações, logo, enquadram-se dentro de um processo de desenvolvimento, que pontualmente perpassa "a ativação de recursos materiais e simbólicos e a mobilização de sujeitos sociais e políticos buscando ampliar o campo de ação da coletividade, aumentando sua autodeterminação e liberdade de decisão" (BRANDÃO 2008, p. 3). Ainda, para o autor (p. 3), "o verdadeiro desenvolvimento exige envolvimento e legitimação de ações disruptivas, portanto envolve tensão, eleição de alternativas e construção de trajetórias históricas, com horizontes temporais de curto, médio e longo prazos".

As cooperativas de produtores rurais atuam na organização da produção e na prestação de serviços aos associados, auxiliando em aspectos como: escoamento da produção, assessoria técnica, qualidade, manejo da produção, tecnologia, beneficiamento do produto, capacitação e propagação de conhecimento, informações para o empreendimento e relacionamento com outros produtores. Com base nisso, são capazes de agregar valor aos produtos, além de buscar obter maior produtividade e rentabilidade para as atividades, que no conjunto visam ao aumento da renda e a outros benefícios dentro do seu papel 
social (SILVA; LAGO, 2010).

Além desses aspectos, outros podem ter sido relevantes para 0 desenvolvimento regional, conforme será demonstrado a seguir.

\subsection{Aspectos relevantes para o desenvolvimento regional}

Desenvolvimento é um processo pluridimensional e dinâmico (BRANDÃO, 2008). Exige uma compreensão mais ampla, além da visão de crescimento, que é uma condição atrelada ao desenvolvimento, mas que não o define por completo; desenvolvimento pressupõe a composição e evolução de variáveis quantitativas e também qualitativas.

De acordo com Brandão (2008, p. 3), “o desenvolvimento enquanto processo multifacetado de intensa transformação estrutural resulta de variadas e complexas interações sociais que buscam o alargamento do horizonte de possibilidades de determinada sociedade". Esse processo deve ser promovido simultaneamente em várias dimensões (produtiva, social, tecnológica, etc.) e em várias escalas espaciais (local, regional, nacional, global, etc.), de modo a fortalecer a autonomia e a ação dos seus agentes.

De acordo com Amaral Filho (2001), os novos modelos de desenvolvimento regional condizem com ações descentralizadas das empresas e das instituições públicas e promovem um processo de reciprocidade entre os mesmos, uma relação de cooperação e concorrência sob uma lógica de funcionamento extrovertida, com maior valorização ao território inserido.

Para Marini e Silva (2012), a expansão do sistema capitalista e da industrialização a partir do século $X X$ provocou maior compreensão da sociedade sobre o desenvolvimento econômico endógeno, que considera os ativos territoriais, as forças produtivas locais, a concentração espacial das empresas e os movimentos de agentes locais. Esta visão contrapõe-se à visão tradicional de que fatores exógenos à região seriam responsáveis por promover o seu desenvolvimento.

O desenvolvimento econômico regional resulta, nesse sentido, de uma ênfase atribuída às dinâmicas locais, devendo-se considerar a história e a cultura regional, respeitando diferenças entre localidades, o comprometimento social institucional, a formação de capital social e a confiança entre os indivíduos, os quais se dispõem à coletividade e facilitam, inclusive, o crescimento econômico (VIEIRA; SANTOS, 2012). O Estado contribui economicamente para o desenvolvimento regional, todavia, não devem ser desconsideradas as dimensões culturais e sociais de cada região, de modo que o desenvolvimento regional seja um papel definido em conjunto e que as regiões cultivem seu próprio desenvolvimento (CHOUINARD; DESJARDINS; FORGUES, 2002).

É significativa a atuação dos agentes locais e uma identidade regional fortalecida, no sentido de conduzir um processo de desenvolvimento, integração e consecução de objetivos comuns (BANDEIRA, 1999). Diante disso, a valorização de aspectos endógenos e diversos e a participação dos agentes locais podem firmar uma estrutura para um desenvolvimento comprometido e mais durável. Os territórios em desenvolvimento são formados pela maneira como se organizam e isso envolve fatores como seus modelos mentais, forma de falar, trajetórias 
comuns e a coordenação e conhecimentos tácitos produzidos pela interação entre indivíduos e organizações (BEDUSCHI FILHO; ABRAMOVAY, 2004).

No meio rural, o desenvolvimento endógeno envolve a adaptação e a manutenção de um portfólio de atividades para garantir uma sobrevivência segura. A diversificação se torna uma forma de reduzir a pobreza, aumentar o emprego e a renda (ELLIS, 2000). É preciso, entretanto, que essa diversificação esteja em consonância com as características e as condições da região, visto que não se trata de um fenômeno transitório (ELLIS, 2000) e, assim, impacta sobre os modos de vida e o desenvolvimento regional como um todo.

O Oeste Catarinense tem um forte tecido sociocultural que envolve seu potencial regional para atividades agropecuárias, associativas e de diversificação produtiva. É preciso, portanto, que o desenvolvimento seja compreendido pela sua construção endógena, contextualizada, ou seja, envolvendo tais características e garantindo a sobrevivência segura dos produtores no meio rural.

\section{METODOLOGIA}

O objetivo dessa pesquisa foi fazer uma reflexão sobre a evolução histórica ocorrida na pecuária leiteira no Oeste Catarinense nos últimos anos, e sua relação com o desenvolvimento regional. Esse trabalho tem abordagem qualitativa e utiliza-se de técnicas de coletas de dados primários e secundários para construir uma descrição da evolução na pecuária para os produtores rurais. A abordagem qualitativa parece adequada para esta temática, pois faz-se um resgate sobre as dinâmicas ocorridas na região de estudo, o que pode fornecer novas perspectivas sobre a mesma, seguindo uma linha de pesquisa como a proposta por Silverman (2009).

Os dados qualitativos foram obtidos em entrevistas com roteiro semiestruturado, realizada com sete especialistas (pesquisadores e professores de instituições como Epagri, Universidade Comunitária da Região de Chapecó Unochapecó, Univesidade Federal de Santa Catarina - UFSC, Cooperativas e Associações). O roteiro de entrevista contemplou a inserção e o desenvolvimento da pecuária leiteira na região nos últimos anos e a sua colaboração para o desenvolvimento regional. Os dados secundários foram obtidos em bancos de dados como IBGE e publicações especializadas.

Cada entrevista foi gravada e durou entre 40 minutos e 1 hora. A escolha dos especialistas se deu pela técnica de bola de neve, em que foi consultado um especialista, solicitando-se que indicasse outro para responder às mesmas perguntas, até que se esgotassem as possibilidades. Depois de transcritas as entrevistas, realizou-se a análise das respostas buscando contemplar pontos comuns entre os respondentes e sua relação com aspectos teóricos relevantes.

\section{DISCUSSÃO E RESULTADOS}

A inserção da pecuária leiteira na matriz produtiva do Oeste Catarinense ocorreu por necessidade e estratégia. É consenso entre os entrevistados de que a produção de leite atrai os produtores pela estabilidade (a produção é diária e a 
renda mensal), pelo baixo custo, a possibilidade de ser competitivo e reproduzir-se socialmente como produtor rural. Dois entrevistados relatam que, afora a pressão da indústria e do mercado, o leite se enquadra como uma atividade resultante de estratégias de sistemas de produção adotadas pelos produtores rurais, de acordo com os recursos internos disponíveis (como terra, mão de obra, capital) e as oportunidades de mercado. Para um dos entrevistados,

\begin{abstract}
uma estratégia forjada pela agricultura familiar, que a gente às vezes negligencia, acha que o agricultor não tem estratégia, e ele tem estratégia na construção dos seus sistemas produtivos. Eles fazem a opção, e a gente acha que eles não fizeram a opção. Mas fizeram. Tem avicultores que não concretizaram seus aviários, eles desistiram da avicultura, pegaram o dinheiro da avicultura, o pouco que dá, investe no leite e deixa o aviário sucatear. Vão desistir da avicultura, porque não dá pra tocar duas atividades e tal. Eu sou muito otimista nesse sentido de que o agricultor familiar, quando é possível, ele implementa estratégias de gestão, de inserção no mercado (ENTREVISTADO No 3).
\end{abstract}

Por essa perspectiva, tem-se o que Ellis (2000) entende como determinantes da pluriatividade: necessidade ou escolha. Se em um momento a pecuária leiteira pode se tornar uma atividade comercial por necessidade de renda, no segundo momento ela se torna uma escolha, inclusive estratégica.

Além disso, infere-se que recursos locais (econômico, cultural, social) encontram seu valor estratégico no desenvolvimento socioeconômico das regiões, conforme Chouinard, Desjardins e Forgues (2002). Acessar recursos locais e evitar que sejam subjugados por interesses de outros deve ocorrer em um contexto onde o desenvolvimento corresponda ao interesse geral da comunidade, privilegiando os benefícios de uma abordagem equilibrada em que as exigências de mercado e o interesse da comunidade são ambos considerados.

A transição entre as atividades de suinocultura e avicultura para a pecuária leiteira não ocorreu no sentido de exclusão ou total abandono das primeiras. Houve um "movimento social" construído para viabilizar essa transição, uma mobilização de diferentes atores no sentido de capitalizar, organizar e comercializar a produção de leite, especialmente nos fins dos anos $1980 \mathrm{em}$ diante. Articularam-se atores sociais regionais, como afirmaria Bandeira (1999), no sentido de formar consensos relevantes para a competitividade e o desenvolvimento de uma região.

A produção de leite era, inicialmente, pulverizada em diferentes microrregiões do Oeste Catarinense, de forma mais difusa, e teve um crescimento maior que abrange todo o território a partir de fins da década de 1990 e início dos anos 2000. Houve, entretanto, segundo os entrevistados, uma redução no número de produtores desde a década de 1980, mas um aumento em termos de produtividade. Muitos produtores que tinham o queijo como produto comercial da atividade leiteira passaram, então, a comercializar também o leite cru, o que, para um dos entrevistados, representou uma commoditização do leite e que levou os produtores a um sistema competitivo desfavorável à atividade.

O leite como commodity contrapõe-se à diversificação ou pluriatividade. Porém, como afirma Mior (2008), o leite está ainda em um processo em transição, com estratégias distintas, que incluem a transformação da 
produção artesanal para commodity até a construção de produtos com qualidade diferenciada (colonial, orgânico, agroecológico, etc.).

Ao que se refere à situação da pecuária leiteira na região Oeste Catarinense nos últimos anos, os entrevistados apontaram a ocorrência de pressão pela indústria e pelas exigências legais como a IN51, gerando um "enforcamento" e desestímulo das indústrias sobre os produtores, processo de exclusão e consequente concentração de produtores. O atendimento à legislação serviria como "ponto de corte" da qualidade, definindo o patamar mínimo de qualidade exigido na produção. Ao mesmo tempo em que a IN51 e a IN62 determinam regras, elas viabilizam políticas públicas e ações do Estado que poderiam evitar a exclusão de produtores da atividade (em função das pressões de mercado).

Para os entrevistados, há pouco incentivo por parte das indústrias e das políticas públicas no sentido de manter ou industrializar a produção nas pequenas cooperativas da região. Isso é também inviabilizado pelo alto custo de manter análises mensais de leite, pela falta de confiança do mercado nas indústrias do leite e pelos diversos jogos políticos em torno destas.

Outro aspecto presente nos últimos anos é o preço instável, bem como a variação na produção em períodos de seca. A dificuldade de logística em função da pulverização das propriedades rurais na região ainda é apontada como um fator estratégico negativo que tem melhorado de forma gradual. De maneira geral, os entrevistados entendem que faltam políticas específicas que incentivem a compra de matérias-primas para estruturar a produção.

Apesar da existência de programas como o Programa Nacional de Fortalecimento da Agricultura Familiar - Pronaf, por exemplo, voltados à capitalização de atividades agrícolas, bem como recursos do governo para famílias carentes, gerando aumento de renda da população, programas de merenda escolar, apoio para compra de equipamentos, a eficácia dos programas ainda é questionada por alguns entrevistados.

Dentre os desafios da pecuária leiteira está a dificuldade em manter a força de trabalho no meio rural, manejar processos de sucessão familiar, acessar técnicas novas de produção, envolvendo aspectos de solo, pastagem, sanidade e ciclo fisiológico da reprodução do animal. Segundo um dos especialistas ( $n^{\circ} 6$ ), não se trata de aumentar a produção, mas de saber utilizar os recursos que se tem. A atividade leiteira não permite férias, exige cuidado diário, permite o uso de terrenos acidentados e do pasto e, segundo os especialistas, a lógica camponesa responde bem a essa demanda.

Mesmo com os benefícios naturais que a região proporciona, como o solo e o clima propícios à pecuária leiteira, a demanda por assistência técnica é frequente, e não é atendida na maior parte dos casos, estando disponível para poucos produtores. Por um lado, a indústria não tem interesse em fornecer para todos os produtores esse tipo de assistência e, por outro, as cooperativas ainda estão muito centradas no produto, deixando de lado outros aspectos de apoio ao produtor. Ou seja, a assistência técnica é mal distribuída entre os produtores. Como afirma um entrevistado: "não existe uma identidade direta entre o pequeno volume de leite e a pequena área de terra. Portanto não dá pra dizer que se está deixando os pobres de lado, os que não têm terra de lado". A solução é que a assistência técnica depende muito de pró-ação do produtor. 
A atividade leiteira exige um conhecimento básico, que praticamente todo produtor sabe fazer, na opinião dos especialistas. Por esse motivo, somado à vocação da região, o Sul vai ser a principal bacia leiteira do Brasil até 2015/2020. Aproveita-se a aprendizagem obtida com as experiências anteriores: o Oeste Catarinense já teve a experiência negativa na suinocultura, com os consórcios que não deram certo em outro contexto, e com o leite, hoje, está sendo diferente:

\begin{abstract}
a trajetória organizacional dos agricultores permite construir estratégias mais adequadas do ponto de vista da agricultura familiar, que é escala diferenciada, produção organizada pela base, padrão tecnológico diferenciado, a industrialização descentralizada e o mercado para produtos diferenciados (ENTREVISTADO No 3 ).
\end{abstract}

Diferentemente da suinocultura, em que a raça e a genética definem a qualidade do produto, e da avicultura, em que o produtor não decide nada sobre a produção (apenas o horário de alimentar os animais), no caso do leite, o básico é a higiene, mas ele decide o manejo, a forma de criar. Assim, a autonomia do produtor é maior. A qualidade e a forma de consumo ainda dependem muito do consumidor, da regulação, do que acontecer no âmbito político-estratégico do governo federal, com o uso de mecanismos como o Sistema Único de Atenção à Sanidade Agropecuária - Suasa, IN51, IN62, indicações geográficas, produção orgânica e valorização de produtos diferenciados.

De maneira geral, então, têm-se desafios e oportunidades que estão se viabilizando, principalmente, pela constituição de redes, em movimentos sociais que buscam capacitar, assessorar e orientar os produtores, inclusive na busca de recursos. Reflete-se que há espaço para formas associativas, que são significantes na articulação de demandas econômicas e sociais dos associados, além do envolvimento com ações mais amplas que se preocupem com o desenvolvimento da região.

A APACO e a Ascooper são referências de organização na região estudada, que dedicam atenção à produção rural e também à atividade leiteira. Se de um lado os produtores se sentem pressionados por determinadas manobras das indústrias e exigências impostas, por outro, tem-se uma ferramenta estratégica para organizar os produtores familiares em projetos e programas que envolvam os agentes locais, em contraposição ao modelo tradicional de modernização agrícola.

Os produtores rurais no Oeste Catarinense, antes de ingressar em redes, tendem a produzir e comercializar na informalidade, inclusive partilhando com vizinhos da comunidade suas máquinas e equipamentos. Eles estão "imersos nas redes locais, formadas por relações sociais e de vizinhança, onde constroem o mercado de seus produtos coloniais" (DORIGON, 2008, p. 300). Contudo, com a competitividade crescente entre os produtores, há uma forte tendência ao abandono da cultura cooperativista e a busca pelos ganhos individuais (WINCKLER, SANTOS, MACHADO, 2013). Esse é um problema presente em estruturas cooperativas, quando há opção do ganho individual em detrimento do coletivo (BIALOSKORSKI NETO, 2000).

Contudo, o formato de cooperativas têm ajudado os produtores de leite a contornar os desafios da atividade leiteira, permitindo a reprodução socioeconômica da agricultura familiar. Além disso, através da mobilização por 
redes, os agricultores familiares têm ampliado a complexidade dos seus empreendimentos, segundo Mior (2008), constituindo agroindústrias que processam leite e outros produtos. As agroindústrias familiares também se organizam na forma de associações, contando com o apoio de cooperativas de produtores e de outros agentes, inclusive para desenvolver o uso de marcas e selos coletivos.

Pode-se dizer que o ponto crítico da produção leiteira tem sido a obtenção de maior produtividade e qualidade. Para superar essas barreiras, as cooperativas têm buscado desenvolver iniciativas. A assistência técnica é um suporte importante, a fim de que o produtor tenha disponível informação e orientação para melhor conduzir sua atividade. Esse apoio já foi mencionado como urgente para o produtor de leite e que não abrange grande parte dos produtores, mas que também fica sujeito à deliberação destes.

As exigências de qualidade do leite são cada vez maiores, notadamente com a introdução da IN51 e a sua posterior atualização para a IN62. Logo, a assessoria técnica pode incentivar e auxiliar os produtores a se adequarem às normas. Destaca-se que algumas cooperativas têm adotado a prática de pagamento pela qualidade do leite. A intenção é bonificar o leite que apresente qualidade, visando a estimular a melhoria crescente da produção leiteira (WINCK, 2012). Entre outras justificativas para essa prática, segundo o autor, está o atendimento à nova legislação (IN62). A aquisição do refrigerador é um investimento alto e o seu uso não está diretamente relacionado à produtividade, por isso, essa bonificação pelo produto incentiva o emprego de equipamentos que confiram maior qualidade.

Há também apoio oferecido para a compra de equipamentos e para a melhoria das instalações (resfriadores, ordenhadeiras, etc.), o que motiva o alcance de qualidade e produtividade nas propriedades. Situa- se, assim, o papel do crédito na questão do investimento e do custeio da produção para o pequeno produtor especialmente. $\mathrm{O}$ acesso ao crédito tem sido facilitado por programas com juros mais baixos, o já citado Pronaf. Cooperativas de crédito rural da região também dispõem linha de crédito que atendem ao produtor e às cooperativas de leite.

As cooperativas ainda estariam mais focalizadas no produto. Referindo-se à participação dos agricultores nas cooperativas, de todo modo, um dos entrevistados considera fundamental a relação de coletividade criada e que motiva uns aos outros. À medida que os produtores compartilham experiências, especialmente mediante as dificuldades, levando-os a entender e enfrentar o ambiente competitivo da agricultura. Para ele, a atuação das cooperativas é significativa não somente na questão de buscar uma melhor remuneração para o produto, mas também como processo educativo e de melhoria da produção por meio das cooperativas.

A respeito da colaboração da atividade leiteira para o desenvolvimento regional, obtiveram-se as seguintes respostas: o leite passou a ter importância especialmente após a década de 1990, em meio a um período de depressão econômica na região. Com o empobrecimento regional, o êxodo rural, os períodos de seca em 1996 e 1997, e a dependência dos produtores rurais em relação às indústrias de aves e suínos, era preciso fortalecer os agricultores para que pudessem se manter e reproduzir suas atividades produtivas.

Um dos especialistas aponta três fatores principais para que o leite se 
tornasse um dos elementos-chave na matriz produtiva regional: a adoção de grãos transgênicos nas lavouras agrícolas de soja, que fez com que muitos pequenos produtores tentassem investir nessa atividade; os sistemas de integração e verticalização na indústria avícola e suinícola, em que o produtor agrícola ficasse dependente do controle das indústrias, tornando-se apenas fornecedor de matériaprima e tendo desconsiderados aspectos sociais envoltos na sua situação no campo; a saída de jovens e casais de jovens para trabalhar e estudar na zona urbana. Apesar desses aspectos, segundo o especialista, "o leite fez sucessão, se tornou uma alternativa econômica, de pouco investimento, fácil logística, com a ideia de uso do pasto e da renda mensal, que é diferente da produção de lavoura em que a renda é anual" (ENTREVISTADO № 2).

Observa-se, assim, uma disposição que recorre a recursos locais. De acordo com Chouinard, Desjardins e Forgues (2002), quando a dinâmica imposta pelo mercado se sobrepõe, as regiões ficam sujeitas aos efeitos negativos da inadaptabilidade para determinada economia. Logo, em reação, essa disposição e a vontade coletiva podem ser vistas como contribuintes para que tomem suas decisões e cuidem de seu próprio desenvolvimento.

Amaral Filho (2001) ressalta que as regiões no interior dos países vêm mostrando um movimento de endogeneização, tanto das decisões relacionadas ao seu destino quanto do uso dos meios e dos recursos utilizados no processo econômico. Nesse contexto, para outro especialista, além de alternativa de renda, o leite permite o desenvolvimento endógeno porque tem importância econômicae permite produzir sem mecanização extrema. Por isso se tornou uma

\footnotetext{
âncora da região porque consegue combinar uma série de fatores que diferentemente de outras atividades tem um alto valor agregado. Tem algumas estimativas que mostram que o leite tem uma capacidade de produção endógena, você produz a partir do "nada", tem a fertilidade do solo que você está extraindo, tem a água, tem a mão de obra familiar, e você tem poucos insumos externos, o que faz com que o valor adicionado seja muito alto no leite (ESPECIALISTA No 3 ).
}

As cooperativas de leite têm forte impacto institucional para viabilizar a atividade produtiva, porque coletam leite em propriedades de alta e baixa produção, em função da importância social que possuem esses pequenos produtores. Além disso, o dinheiro gira nos municípios em que há produção e cooperativas. Para um dos entrevistados, a pecuária leiteira é "uma atividade econômica, com impacto social. Por conta do numero de famílias que ela atinge, por conta dessa renda, não só em termos de volume de renda, mas da distribuição mensal dela para as familias, tem um impacto fundamental do ponto de vista social" (ESPECIALISTA No 6).

Pode-se afirmar que "é uma atividade que tem gerado a longo e médio prazo a possibilidade de viabilização econômica, mas também de reprodução social" (ESPECIALISTA No 7). As cooperativas promovem um ciclo benéfico para produtores, cooperativas e município, pois

a cooperativa de crédito libera uma pessoa pra trabalhar a produção, consequentemente aumenta a produção do leite, a cooperativa de crédito financia a compra de adubo orgânico, então, consequentemente, 
toda a pastagem vai ter uma maior produção, e automaticamente tu vai produzir mais dinheiro, isso é desenvolvimento endógeno. O papel da cooperativa de crédito no local é que faz circular o dinheiro dentro do município o máximo possível. Se hoje fosse tirada a atividade do leite de alguns municípios pequenos fecham as portas, eles são devolvidos e se "desemancipam" (ESPECIALISTA № 5).

Logo, cooperativas e sua forma associativa de organização encontram valor no desenvolvimento das atividades e também da região. Por isso, é imprescindível o comprometimento com suas funções econômica e social. Além disso, conforme Ilha (2008), para fazer parte do capital social e contribuir com o desenvolvimento regional, a cooperativa não pode se abster de questões que envolvem as necessidades da comunidade.

$\mathrm{Na}$ ocasião das entrevistas, a pecuária leiteira não foi apontada como a principal atividade econômica da região, mas para os especialistas, ela se tornará. O leite tem colaborado na reprodução da agricultura familiar e se mostrado como a principal atividade social da região. Porém, segundo os especialistas, no aspecto ambiental, ao mesmo tempo em que a atividade explora áreas não propícias para a lavoura, ela tem o risco de explorar áreas não propícias para o pasto, podendo gerar erosão e compactação do solo. Ainda assim, ela está em vantagem quanto ao seu impacto ambiental se comparada com a produção de suínos e aves. Portanto, envolve benefícios econômicos, sociais e ambientais.

Disso tudo, a atividade leiteira na região demonstra ativar elementos endógenos. Organizações associativas, por sua vez, promovem a inserção e articulam apoio em diferentes instâncias para organizar, capacitar, negociar e pleitear recursos. Mesmo que, no caso das cooperativas, seja ainda uma dificuldade o fato de estarem mais focadas no produto. De qualquer forma, vai se estabelecendo uma nova dinâmica, que resguarda características locais, com a cooperação que confronta a competitividade e, em especial, possibilita que produtores, junto a demais agentes, formem liderança na condução do seu desenvolvimento. Dentro desse contexto, é significativa a valorização dos produtores rurais e dos aspectos peculiares à região.

\section{CONSIDERAÇÕES FINAIS}

Para finalizar este trabalho, há alguns aspectos a se destacar a partir das entrevistas com os especialistas:

Em termos de produção e geração de renda, o leite é uma alternativa viável porque conta com recursos locais, desde o conhecimento do produtor, a força de trabalho familiar, as condições geográficas e topográficas locais que beneficiam a produção, a geração de renda mensal e a permanência do trabalhador no campo;

Fatores institucionais, legais e mercadológicos que vinham pressionando os produtores de suínos e aves estão, paralelamente, oportunizando-se e pressionando aos produtores de leite também, influenciando sobre as suas estratégias para a manutenção das atividades. São exemplos desses fatores os incentivos oferecidos pelo Pronaf e por outras fontes de renda, bem como as pressões mercadológicas das indústrias de laticínios e a formação de cooperativas nos últimos anos; 
A dinâmica produtiva regional demonstrada pela mudança do padrão produtivo de suínos e aves para o quase protagonismo do leite, como apontado pelos entrevistados, envolve a trajetória dos produtores rurais, essencialmente, e como respondem às pressões institucionais e de mercado.

Em suma, o leite tem sido um dos protagonistas do desenvolvimento regional no Oeste Catarinense nos últimos anos. As evidências apontadas pelos especialistas denotam que, não fosse a pecuária leiteira, muitos produtores teriam abandonado o meio rural, desconsiderando os potenciais decorrentes das características locais.

Esse trabalho não esgota essa temática, que é tão relevante para o Brasil e, especialmente, para as suas diferentes regiões. Conhecer a trajetória de desenvolvimento de uma região permite compreender quais os pontos altos e baixos que lhe permitem se destacar em determinadas atividades e promover a melhor distribuição populacional e da renda no país.

Como limitações, este trabalho não aprofunda questões econômicas como PIB dos municípios, percentual de participação da produção de leite em cada município e propriedade rural e de agregação de valor ao longo da cadeia produtiva, que seriam indicadores interessantes para constatar, na prática, como o leite impacta na economia familiar e municipal. Além disso, dado o tempo, o espaço e os recursos disponíveis para esta pesquisa, não foi possível aprofundá-la in loco, permanecendo, portanto, no campo das ideias e concepções dos especialistas consultados e das autoras.

Como sugestões para trabalhos futuros, menciona-se a investigação dos aspectos de sustentabilidade comparada entre as atividades produtivas da região Oeste Catarinense, bem como a análise sob um viés econômico do desenvolvimento regional.

\section{REFERÊNCIAS}

ALVES, P. A.; MATTEI, L. F. Migrações no Oeste Catarinense: História e Elementos Explicativos. In: ENCONTRO NACIONAL DE ESTUDOS POPULACIONAIS, 15., 2006, Caxambu. Anais... Caxambu, 2006.

AMARAL FILHO, J. A endogeneização no desenvolvimento econômico regional e local. Planejamento e Políticas Públicas, Brasília, n. 23, p. 261-286, 2001.

ANDION, C. Atuação das ONGs nas dinâmicas de desenvolvimento territorial sustentável no meio rural de Santa Catarina: os casos da APACO, do Centro Vianei de Educação Popular e da Agreco. 2007. 427f. Tese (Doutorado - Ciências Humanas) - Programa Interdisciplinar em Ciências Humanas, Universidade Federal de Santa Catarina, Florianópolis, 2007.

BADALOTTI, R. M. A Cooperação Agrícola e Agroecologia como base para a viabilização da agricultura familiar no Oeste Catarinense: o papel da APACO e demais agentes sociais. 2003. 287f. Tese (Doutorado - Ciências Humanas) Programa Interdisciplinar em Ciências Humanas, Universidade Federal de Santa 
Catarina, Florianópolis, 2003.

BANDEIRA, P. Participação, articulação de atores sociais e desenvolvimento regional. Brasília, 1999. (Texto para Discussão IPEA, n. 630). Disponível em: <http://www.unc.br/mestrado/mestrado_materiais/texto_pedro_bandei ra_n.630.pdf >.

BEDUSCHI FILHO, L. C.; ABRAMOVAY, R. Desafios para o desenvolvimento de regiões rurais. Revista Nova Economia, v. 14, n. 3, set/dez, 2004, p. 35-70.

BIALOSKORSKI NETO, S. Agribusiness Cooperativo. In: ZYLBERSZTAJN, D.; NEVES, M. F. Economia e Gestão dos Negócios Agroalimentares. São Paulo: Pioneira, 2000.

BRANDÃO, C. Desenvolvimento, Territórios e Escalas Espaciais: levar na devida conta as contribuições da economia política e da geografia crítica para construir a abordagem interdisciplinar. In: RIBEIRO, M. T. F.; MILANI, C. R. S. (Orgs.).

Compreendendo a complexidade sócio-espacial contemporânea: o território como categoria de diálogo interdisciplinar. Salvador: Editora da UFBA, 2008.

CHOUINARD, O.; DESJARDINS, P. M.; FORGUES, E. Collective Entrepreneurship and Regional Development: Case Study of a New Brunswick Cooperative. Journal of Rural Cooperation, v. 30, n. 2, p. 79- 94, 2002.

DORIGON, C. Mercados de produtos coloniais da região Oeste de Santa Catarina: em construção. 2008. 454f. Tese (Doutorado - Ciências) - Instituto Alberto Luiz Coimbra de Pós-graduação e Pesquisa de Engenharia, Universidade Federal do Rio de Janeiro, Rio de Janeiro, 2008.

ELLIS, F. The determinants of rural livelihood diversification in developing countries. Journal of Agricultural Economics, v. 51, n. 2, 2000, p. 298-302.

IBGE. Instituto Brasileiro de Geografia e Estatística. Censo Agropecuário de 2006. Disponível em:

<http://www.sidra.ibge.gov.br/bda/pesquisas/ca/default.asp?o $=2 \& \mathrm{i}=\mathrm{P}>$. Acesso em 20 ago. 2014.

ILHA, P. C. S. A cooperativa como elemento de capital social da comunidade.

Revista da FAE, Curitiba, v. 11, n. 2, p. 25-34, 2008. MAGALHÃES, R. S. Habilidades Sociais no Mercado de Leite. In: ENCONTRO NACIONAL DA ANPOCS, 30., 2006, Caxambu. Anais...Caxambu, 2006.

MARINI, M. J.; SILVA, C. L. da. Desenvolvimento Regional e Arranjos Produtivos Locais: uma abordagem sob a ótica interdisciplinar. Revista Brasileira de Gestão \& Desenvolvimento Regional, v. 8, n. 2, mai/ago, 2012, p. 107-129.

MEDEIROS, S. S.; VALENCIO, N. F. L. S. Representações e práticas tradicionais diante da inovação tecnológica: o caso do projeto "Balde Cheio" da Embrapa. Teoria e Pesquisa: Revista de Ciências Sociais, São Carlos, v. 17, n. 1, p. 135163, 2008.

MIOR, L. C. Trajetória das Agroindústrias Familiares Rurais no Estado de Santa 
Catarina (Brasil). In: CONGRESO INTERNACIONAL DE LA RED SIAL, 4., 2008, Mar Del Plata. Anais... Mar Del Plata, 2008.

OCB. Organização das Cooperativas Brasileiras. Relatório OCB 2013. Brasília: OCB, 2014.

PAIM, E. A. Aspectos da Constituição Histórica da Região Oeste de Santa

Catarina. Saeculum - Revista de Histórica, João Pessoa, n. 14, p. 121- 138, 2006.

RIOS, G. S. L. O que é cooperativismo. São Paulo: Brasiliense, 2007. ROVER, O. J.; LANZARIN, A. O cooperativismo de leite do Oeste de Santa Catarina/Brasil e a inclusão sócio-econômica de agricultores familiares em condições vulneráveis. In: ENCONTRO DE PESQUISADORES LATINO- AMERICANOS DE COOPERATIVISMO, 5., 2008, Ribeirão Preto. Anais... Ribeirão Preto, 2008.

SCHUBERT, M. N.; NIEDERLE, P. A. Estratégias competitivas do cooperativismo na cadeia produtiva do leite: o caso da Ascooper, SC. In: CONGRESSO DA SOBER, 47., 2009, Porto Alegre. Anais... Porto Alegre, 2009.

SILVA, T. N.; LAGO, A. A sociedade e o cooperativismo agropecuário. In: CONGRESO LATINOAMERICANO DE SOCIOLOGIA RURAL, 8., 2010, Porto de Galinhas. Anais... Porto de Galinhas, 2010.

SILVERMAN, D. Interpretação de Dados Qualitativos: métodos para análise de entrevistas, textos e interações. 3 Ed. Porto Alegre: Artmed, 2009.

TESCHE, R. W. As relações de reciprocidade e redes de cooperação no desempenho socioeconômico da agricultura familiar: o caso dos produtores de leite do município de Sete de Setembro. 2007. 149 p. Dissertação (Mestrado) Programa de Pós-Graduação em Desenvolvimento Rural, Universidade Federal do Rio Grande do Sul, Porto Alegre, 2007.

VIEIRA, E. T.; SANTOS, M. J. Desenvolvimento econômico regional - uma revisão história e teórica. Revista Brasileira de Gestão \& Desenvolvimento Regional, v. 8, n. 2, mai/ago, 2012, p. 344-369.

WINCK, C. A. Perfil das propriedades leiteiras em Santa Catarina e sua relação com a adequação às normas brasileiras de qualidade do leite. 2007. 88f.

Dissertação (Mestrado) - Centro de Ciências Agroveterinárias, Universidade do Estado de Santa Catarina, Lages, 2007.

Impactos do pagamento pela qualidade na cadeia produtiva do leite na região Oeste de Santa Catarina. 2012. 119f. Tese (Doutorado - Agronegócios) - Centro de Estudos e Pesquisa em Agronegócios, Programa de Pós-Graduação em Agronegócios, Universidade Federal do Rio Grande do Sul, Porto Alegre, 2012.

WINCKLER, N. C.; SANTOS, T. S.; MACHADO, J. A. D. A coopetição entre produtores familiares na cadeia produtiva do leite no oeste catarinense. Revista Brasileira de Gestão e Desenvolvimento Regional, v. 9, n. 1, 2013. 
Submetido em 19/10/2014

Aprovado em 24/11/2015

\section{Sobre as Autoras}

Natália Carrão Winckler

Administradora (Universidade de Passo Fundo), Mestre em Agronegócios e Doutoranda em Administração (Universidade Federal do Rio Grande do Sul). Professora no Instituto Federal Sulrio-grandense.

Endereço: IFSul - Campus Sapucaia do Sul - Av. Copacabana, 100 - Bairro Piratini. 93216120 - Sapucaia do Sul - RS - Brasil.

E-mail: nataliawinckler@sapucaia.ifsul.edu.br

\section{Gisele Trindade Molinari}

Economista (Universidade Federal de Santa Maria), Mestre em Agronegócios

(Universidade Federal do Rio Grande do Sul)

E-mail: gisele-molinari@hotmail.com 